\title{
The impact of lifestyle factors on evolution of atopic dermatitis: An alternative approach (Review)
}

\author{
IULIA SOLOMON ${ }^{1}$, MIHAELA ADRIANA ILIE ${ }^{2,3}$, CARMEN DRAGHICI $^{1}$, VLAD MIHAI VOICULESCU ${ }^{1,2}$, \\ CONSTANTIN CĂRUNTU ${ }^{4,5}$, DANIEL BODA ${ }^{2,5}$ and SABINA ZURAC ${ }^{6,7}$ \\ ${ }^{1}$ Department of Dermatology and Allergology, Elias Emergency University Hospital, 011461 Bucharest; \\ ${ }^{2}$ Dermatology Research Laboratory; Departments of ${ }^{3}$ Biochemistry and ${ }^{4}$ Physiology, 'Carol Davila' University of \\ Medicine and Pharmacy, 050474 Bucharest; ${ }^{5}$ Department of Dermatology, 'Prof. N. Paulescu' National Institute of \\ Diabetes, Nutrition and Metabolic Diseases, 011233 Bucharest; ${ }^{6}$ Department of Pathology, Faculty of \\ Dental Medicine, 'Carol Davila' University of Medicine and Pharmacy, 050474 Bucharest; 7 Department of \\ Pathology, Colentina Clinical Hospital, 020125 Bucharest, Romania
}

Received August 13, 2018; Accepted September 26, 2018

DOI: $10.3892 /$ etm.2018.6980

\begin{abstract}
Atopic dermatitis (AD) is a multifactorial chronic inflammatory disease with an incompletely understood etiopathogenesis. With a significant impact on the quality of life of patients, AD has attracted the interest of many research studies aiming to investigate the complex cellular and molecular mechanisms and to identify new therapeutic pathways. Various studies have focused on psycho-immunology, emphasizing the involvement of stress, defined as a general response of the body to external or internal challenges to the AD pathology. Factors like lifestyle and leisure activities may change the behavior of immune cells in AD with a strong impact on the evolution of the disease. Moreover, the poor adherence of $\mathrm{AD}$ patient to standard treatment approach has led to the necessity to combine different therapies in the field of complementary and alternative medicine. Although there are still not enough data to conclude that adjuvant therapies are effective in a conventional sense, there are already promising results suggesting that alternative therapeutic strategies could be a main subject of further research.
\end{abstract}

\section{Contents}

1. Introduction

2. Psychoneuroimmunology of atopic dermatitis

3. Lifestyle factors and leisure activities in atopic dermatitis

4. Discussion

Correspondence to: Dr Constantin Căruntu, Department of Physiology, 'Carol Davila' University of Medicine and Pharmacy, 8 Eroii Sanitari Avenue, 050474 Bucharest, Romania

E-mail: costin.caruntu@gmail.com

Key words: atopic dermatitis, stress, lifestyle, neuroendocrine factors, psychoneuroimmunology, diet, microbioma

\section{Introduction}

Atopic dermatitis (AD) is a chronic relapsing inflammatory skin disease characterized by dry skin, cutaneous inflammation and intense itching which can be exacerbated by many trigger factors such as allergens, infections, season and climate changes or psychological stress. Almost half of the cases are diagnosed by the age of 1 year and more than one third of the patients have a persistent disease throughout adulthood $(1,2)$. Nowadays, AD is one of the most common skin diseases worldwide. However, it is often perceived as a minor dermatologic condition, for which patients have to endure symptoms over time (3). At individual level, it has been depicted that AD has a significant effect on quality of life, more important than other common skin diseases, extending its negative effects on patient's family $(4,5)$. Being frequently associated with asthma, allergic rhinitis, contact dermatitis, food allergies, AD deserves to be analyzed in the light of possible complications (6).

The severity of the disease is assessed based on the intensity of the eczema, by the presentation of elementary lesions (erythema, edema/papule, exudate/wounds, excoriations and lichenification), and on the repercussions of subjective symptoms, such as itching and sleep loss $(7,8)$. Furthermore, it is important to take into account the effects of $\mathrm{AD}$ on patients' lives, the social impact of the disease, how the patients are managing their condition and their opinion regarding how well the disease is controlled.

The main functions of the skin are protection and defense. Impairment of skin barrier affect the defense against the action of external physico-chemical agents and aggression of microorganisms. Most of the barrier defects that have been described in AD originate in the stratum corneum, a main component of skin barrier owning a 'brick and mortar' structure. The surface lipids of stratum corneum provides a filmogenic feature. Also, filaggrin, after hydrolyzed, is responsible for $\mathrm{pH}$ maintenance, moisture and skin protection against microbial agents. On the other hand, proteins of the tight 
junctions are essential to control the selective permeability of the epidermis (9).

There is a wide group of microorganisms that colonize the skin and influence the innate immune response. Predominance of Staphylococcus aureus in active lesions of $\mathrm{AD}$, can exacerbate or contribute to persistent skin inflammation in $\mathrm{AD}$ by secreting toxins with antigenic properties, leading to activation of $\mathrm{T}$ cells and other immune cells (10). In the skin of AD patients were found specific $\operatorname{IgE}$ antibodies directed against the toxins and basophils are able to release histamine on exposure to the relevant toxin $(11,12)$. Moreover, staphylococcal superantigens may induce mast cell degranulation after penetrating the epidermal barrier resulting in pruritus and acute inflammation.

Being a complex, multifactorial disease, therapeutic management of AD is directly dependent on the severity of the condition as well as the patient's compliance (13). Numerous efforts have been directed toward the development of the easiest and most reliable therapeutic strategy for this disease characterized by varied and recurrent symptoms (14). The management of AD is currently focused on avoiding triggers, improving skin hydration and reduction of skin inflammation (15).

In a simplistic note, nowadays, the therapeutic management of AD is represented primarily by emollients associated with the administration of topical steroids and oral antihistamines. This treatment offers a rapid and effective relief of AD symptoms but, it is important to take into consideration that long-term use of corticosteroids may lead to cutaneous adverse events as well as systemic side effects $(16,17)$. Also, ultraviolet therapy may be considered, followed by immunosuppressants such as systemic corticosteroids and cyclosporine $\mathrm{A}$ and topical calcineurin inhibitors (18).

The poor adherence of the patient to drug therapy has made it necessary to combine different therapies in the field of alternative medicine involving the mobilization of physiological and psychological resources. Numerous studies have suggested that balanced lifestyle, healthy diet, hydration, massage, aromatherapy, leisure activities such as listening to classical music, socializing, attending cultural events, altogether could modulate the behavior of patients' immune cells, leading to a favorable evolution of the disease, with a significant decrease in frequency of exacerbations (19-22). Although there are still not enough data to be considered 'effective' in a conventional sense, adjuvant therapies can have promising results that could be the main subject of further research (23-25).

\section{Psychoneuroimmunology of atopic dermatitis}

Already known as a field of study that analyzes the mutual influence of the nervous and immune systems, psycho-neuroimmunology has become the focus of many research studies that seek to find new treatment pathways for diseases such as AD $(26,27)$.

Being a constant aspect of modern life and widely used as a simple term, stress, is defined as a general response of the body to external or internal factors and it has the role of intensely enlivening the physiological and psychological resources of the individual (28). However, it results in an imbalance between the requirements of the body and its ability to cope with it (29). Persistence of stress is known as chronic stress, with repercussions on various organs and systems, especially on the immune system. From the anatomical and physiological point of view, there are several links between the central nervous system (CNS) and the immune system. The most important are represented by the autonomic nervous system (ANS) composed of sympathetic (noradrenergic) and parasympathetic (cholinergic) systems, and the hypothalamic-pituitary-adrenal (HPA) axis (27).

It is well-known that stress related conditions are one of the most worrying political and economic issues in the countries of the European Union, being responsible for producing important social and health care costs (30-32).

Numerous studies have suggested the possibility of stress and neuroendocrine factors being involved in the onset, relapse or worsening of a series of dermatological disorders, such as melanoma and non-melanoma skin cancer, psoriasis, acne, rosacea, vitiligo, alopecia areata, lichen planus, seborrheic eczema, urticaria, prurigo nodularis or AD. Their actions seem to be mediated by neurohormones, neuropeptides, neurotransmitters and neuromediators that modulate the interactions between skin and nervous, immune and endocrine systems (33-38).

Although many studies have attempted to identify a clear-cut correlation between stress and allergic skin diseases, it cannot yet be stated that stress is able to induce an allergic response in any circumstance. However, certain subjects with genetic susceptibility could have a predisposition to develop such conditions.

Stress may induce AD lesions by impairing the skin barrier function (39) and by favoring a switching of the immune response towards a Th2 type lymphocyte response (40-42). These changes may underpin the pathogenic pathways in the onset of the disease. Furthermore, chronic stress is able to reduce the activity of NK cells, leading to an increased vulnerability to infection, hence an aggravation of skin lesions (43).

Another hypothesis of pathogenic mechanism in AD is the increased reactivity of the sympathetic-adrenal medullary system to stress (44) which leads to an imbalance between the adrenergic and cholinergic systems, clinically expressed by paradoxical vasoconstriction to mechanical stimulation of the skin (45).

The activation of neuroendocrine systems as an initial response to stress is different in intensity or duration in any individual subject. In chronic stress, the initial adaptation or adjustment mechanisms aimed to cope with the stress agent stimulate the secretion of various neuropeptides and neurohormones with an important role on the onset and course of the disease $(46,47)$.

For example, secretion of catecholamines and cortisol, major stress hormones, have a significant influence on the immune system. They inhibit the production of IL-12 by antigen-presenting cells (APC), responsible for stimulating the Th1 cell response (48). Moreover, corticosteroids have a direct stimulatory effect on Th2 response, by increasing the levels of interleukins IL-4, IL-10 and IL-13 (49,50). Thus, chronic stress may induce an imbalance of Th1/Th2 responses in favor of the Th2-mediated response, with impairment of neuroimmunological homeostatic mechanisms, favoring the occurrence of an allergic inflammatory response. 
Moreover, stress may induce modulatory actions on cutaneous nerve fibers and their neurons of origin. An increased density of nerve fibers has been emphasized, especially those containing substance P (SP), in AD lesions (51-57). In addition, patients with $\mathrm{AD}$ have significant changes in plasma and tissue levels of neuropeptides such as vasoactive intestinal peptide (VIP), nerve growth factor (NGF), and SP, neuropeptide Y (NPY). Another neuropeptide that could be involved in pathogenesis of AD is calcitonin gene related peptide (CGRP). Higher levels of neuropeptides such as SP, CGRP and VIP induce vasodilation and increased vascular permeability. SP action on monocytes and macrophages increases the production of TNF- $\alpha$ and IL-12, while CGRP stimulates Langerhans cell function to initiate immune responses of Th2 type (58). Furthermore, SP and CRH, released at the peripheral level in inflammatory outbreaks induces mast cell degranulation, thus aggravating the symptoms (59). Mast cells can be another link between stress and exacerbation of AD lesions not only by degranulation of mast cells induced by stress factors, but also by increasing the number of mast cells in the skin $(60,61)$. It was also emphasized that plasma levels of histamine and its concentration in the skin of patients with AD are increased (54).

Thus, there are numerous neuro-pharmacologic agents such as neuropeptides (ACTH, NPY, VIP, SP, CGRP), neurotransmitters [(acetylcholine, noradrenaline, serotonin, histamine, glutamic acid, $\gamma$-aminobutyric acid (GABA)] and hormones (adrenaline and glucocorticoids) involved in the modulation of neuronal receptors that amplify circuits of inflammation. They are all viable options for not only the treatment of $\mathrm{AD}$, but also for other stress-mediated inflammatory skin diseases.

At present it is not possible to explain a direct correlation between stress and several skin diseases, but it is important to take into account the evidence obtained from different studies that support the idea that chronic stress, in genetically susceptible individuals, can favor the onset of AD on the one hand, and can impair the therapeutic control of existing skin disease on the other.

\section{Lifestyle factors and leisure activities in atopic dermatitis}

Emotions. Recent studies have focused increasingly on the emotions rollercoaster, emphasizing their major impact on the development of skin disorders. Moreover, whether acute or chronic, skin conditions have a negative impact on the emotional status of social relationships and on daily activities, due to the stigma caused by the appearance of the lesions (62). Chronic pruritus is often difficult to treat; hence it has a major impact on the quality of life of patients and their families and may lead to psychiatric conditions (32). The decline in the quality of sleep is frequent, affecting the patient's behavior and productivity on a daily basis. Also, in children with AD, sleep loss can lead to hyperactivity disorders and attention deficit. In addition, sleep loss can inhibit recovery of skin barrier increasing natural killer cell activity and plasma proinflammatory cytokines which can worsen the clinical course of many dermatologic conditions $(63,64)$.

Since negative emotions may aggravate the disease, and the disease induces negative emotions it can be said that their entire interaction can create a vicious circle. Also, positive emotions can improve the symptoms of the disease with a significant impact on its evolution $(65,66)$.

Numerous research papers reported the benefits of laughter and many medical researchers from different parts of the world proposed various experiments that measured the physiological effects and benefits of laughter (65). The link between emotion and significant changes on gene activity on cellular level was investigated by Hayashi et al starting from laughter's effect and its potential in treating type 2 diabetes affirming that 'positive emotions influence endocrinological and immunological response' (67).

Kimata showed in a study that laughter reduces the production of allergen-specific IgE, with decreased allergic skin response, significantly increasing the activity of natural killer cells (68).

Regarding deeper feelings, some studies revealed that kissing has a significant effect on allergen induced skin conditions, and decreasing NGF, brain-derived neurotrophic factor (BDNF), neurotrophin-3 (NT-3) and NT-4 levels in patients with AD (69). These results indicate that kissing have appreciable implication in the study of neuroimmunology in AD.

Music. Several studies have investigated the impact of music on skin pathophysiological processes. Kimata emphasized the effects of classical music on patients with latex allergy with a positive response in patients who listened to Mozart's music. However, no response was observed to the patients who listened to Beethoven (70). One of many benefits of music is distracting patients' attention from unpleasant experiences or thoughts with an important impact on patients' quality of life (71). However, the relationship between the immune system and music has been assessed in various research such as the study conducted by Bittman et al (72), who discovered an increased NK cell activity and lymphokine-activated killer cell activity in normal patients. In addition, Koyama et al (73) noted that recreational music modulates immunological responses with significant increases of lymphocytes, $\mathrm{T}$ cells, $\mathrm{CD}^{+} \mathrm{T}$ cells and memory $\mathrm{T}$ cells and higher levels of IFN- $\gamma$ and IL-6. A more recent study by Bittman et al (74) confirmed the above-mentioned findings on a genetic level: their results support the hypothesis that different sets of genes play important roles in both stress and the relaxation response in humans. All these changes may have a huge impact on skin barrier function and the symptomatology of AD patients.

Even though the impact of music was successfully applied in various clinical settings, studies regarding its impact on skin disorders are limited. Nevertheless, nowadays, researchers suggest that listening to known and pleasant music may be included in a regular feature music therapy, aiming to improve the symptomatology of several diseases such as atopic dermatitis, cardiovascular disease, cancer pain, epilepsy, depression and dementia. It would be worthwhile to study the individual emotional responses to music as this would open pathways to tailored music therapy (75).

Humorous movies. Moreover, a considerable correlation between evolution of $\mathrm{AD}$ and watching entertainment TV shows was revealed; specifically, the blood parameters suffered changes as the allergic response diminished. It has been observed that the number of plasma neutrophils has been 
significantly reduced following the viewing of films, thus improving the implicitly mediated allergic response (65).

Furthermore, it was reported that humorous movies are useful in relieving $\mathrm{AD}$ symptoms of children during the night by lowering ghrelin levels. Nighttime waking is quite common in particular in children with AD and disturbances of ghrelin production may be involved in this process. Ghrelin is a hormone produced in the digestive tract, mainly in the stomach and pancreas, which stimulates hunger. It also balances the effect of the hormone leptin produced in the adipose tissue that produces a satiety after the meal (76). Kimata measured salivary ghrelin levels overnight in 40 healthy children and $40 \mathrm{AD}$ patients with nocturnal wake. Levels of salivary ghrelin at 2 AM were significantly elevated in patients with AD compared to those in healthy children. In addition, watching humorous videos before bedtime improved night waking and decreased salivary ghrelin levels in patients with AD (77).

Numerous studies have investigated fluctuations of dermcidin (DCD)-derived peptide, an antimicrobial protein expressed in human eccrine sweat glands. Individuals with atopic eczema have lower levels of DCD-derived peptide in sweat. Researchers measured the levels of DCD protein in the sweat of 20 people before and after watching a humorous movie. They noted a significant increase of this specific protein levels, which could be correlated with the improvement of the skin symptomatology (78).

Mobile phones and video games. Although the sound of mobile phones has come into the daily routine, text messages and video games are included now on the list of factors with a significant influence on AD, increasing both the severity of the symptomatology and the prevalence of the condition. It was estimated that the number of patients with AD increased significantly with the development of technology, making it more and more accessible (79). An interesting research on AD patients undergoing stressful situations (2-h fighting video games or repeated phone calls during a $30 \mathrm{~min}$ interval), highlighted increased values of the prick test response, as well as higher levels of Th2 cytokines, neuropeptides and neurotrophin activity (41). Video games enhanced allergen-specific skin wheal responses in patients with AD, increasing plasma levels of SP and VIP. In addition, mononuclear cells from peripheral blood are stimulated with the combination of IL-4, IL-10, IL-13 leading to allergen-specific IgE hyperproduction with concomitant decreased production of IFN- $\gamma$ and IL-12 in patients with AD. Furthermore, frequent use of mobile phones induces a similar effect, being responsible for an amplification of allergic responses by release of SP, VIP and NGF. The IL-4 and IL-10-stimulated peripheral blood mononuclear cells, lead to an increase in allergen-specific IgE values in AD patients. Since stress can easily aggravate $\mathrm{AD}$, these finding may have important implications in the treatment and pathophysiology of $\mathrm{AD}(80)$.

Diet. The importance of diet as a potential trigger of atopic dermatitis has been a subject of debate for long time $(81,82)$. The pathogenesis of AD associated with food allergy is complex. Imbalance of intestinal flora may have an important role in the development of food allergy in AD, increasing the intestinal permeability that initiates immune responses $(83,84)$. Previous studies emphasized that there are several foods that can aggravate the skin lesions of atopic dermatitis, having an essential and yet unpredictable role in exacerbations of the disease $(85,86)$. Clinical research documented the prevalence of food allergy in AD from $20 \%$ to $80 \%$ (87). Hence, foods such as chocolate, cheese, yogurt, potato chips, glutinous rice cake, instant noodles, eggs, peanuts, seafood, shellfish and milk have been found to be responsible for irregular aggravation of skin lesions in patients with the disease $(88,89)$. Many studies have established several diet instructions that could relieve the symptoms of atopic dermatitis such as: moderation in eating meals with sufficient chewing, avoiding the ingestion of excess sweets, alcohol, coffee, juice, meats, fats, avoiding processed food and additives. However, it is important to adapt the diet as adjuvant therapy for individual patients. Also, a study by Dhar et al (90) on the effects of dietary elimination in 100 children showed significant decrease in the severity score of AD. After 3 weeks of maintaining a proper nutrition, the severity of $\mathrm{AD}$ was measured and showed significant improvement. However, there is not enough evidence that can demonstrate improvement in AD through dietary elimination so this is not recommended routinely as it may lead to a severe nutritional deficiency.

\section{Discussion}

Living with a chronic condition like AD can be both challenging and frustrating. The symptoms such as itching, rash, scaly skin, dryness, bumps, and papules have periods of remission and reappearance, with AD flaring up over and over again (3). It is essential to comprehend that psychological stress affects skin through its direct and indirect effects on immune response, cutaneous neuropeptide expression, and skin barrier function (9). Even though the mechanism underlying the association of AD with psychological stress has not been fully elucidated, many new insights for understanding the role of stress in AD were provided in the field of psychoneuroimmunology (26). There is a growing knowledge about all factors that influence not only the onset, but also the course and severity of this condition, but little is still known about the coping management that may improve its symptoms. There is evidence on the significance of factors such as emotions, sleep, laughter, human interactions, mobile phones, videogames and so on, therefore it is more than relevant to emphasize the link between them and AD (91).

Several studies depicted not only the connection between the nervous and immune system but also the biochemical and cellular links between them (92). It must be taken into account that during chronic stress various hormones and neuropeptides are released leading to immunological changes with imbalance between Th1 and Th2, in favor of the latter.

In conclusion, more and more studies focus on the idea that lifestyle and day-to-day challenges significantly affect susceptible people who are prone to AD. Having all the data, can we conclude that the factors listed are not only responsible for the worsening of $\mathrm{AD}$ but also for the increase of its incidence? 
Studies regarding lifestyle, including every modality of coping with the stress in $\mathrm{AD}$, have a great potential for identifying new therapeutic targets that can improve the treatment of this chronic and relapsing skin disease that has significant impact on patient's quality of life. Even though the research in medicine is continuously undertaken, it is important to emphasize well-being, humor as potential therapeutic interventions, ameliorating atopic eczema and dermatitis. Therefore, using positive emotions as part of the therapy is an outstanding advice not only for patients with AD but also for many other areas of clinical dermatology.

\section{Acknowledgements}

Not applicable.

\section{Funding}

This study was partially supported by a grant of the Romanian Ministry of Research and Innovation, CCCDI-UEFISCDI (project no. 61PCCDI/2018 PN-III-P1-1.2-PCCDI-2017-0341), within PNCDI-III.

\section{Availability of data and materials}

Not applicable.

\section{Authors' contributions}

IS, MAI, CD, VMV, CC, BD and SZ were responsible for gathering and analysis of the data, and contributed to drafting the manuscript and revising it critically for important intellectual content. All authors read and approved the final version of the manuscript.

\section{Ethics approval and consent to participate}

Not applicable.

\section{Patient consent for publication}

Not applicable.

\section{Competing interests}

The authors declare that they have no competing interests.

\section{References}

1. Ellis C, Luger T, Abeck D, Allen R, Graham-Brown RA, De Prost Y, Eichenfield LF, Ferrandiz C, Giannetti A, Hanifin J, et al; ICCAD II Faculty: International Consensus Conference on Atopic Dermatitis II (ICCAD II): Clinical update and current treatment strategies. Br J Dermatol 148 (Suppl 63): 3-10, 2003.

2. Pickett K, Loveman E, Kalita N, Frampton GK and Jones J: Educational interventions to improve quality of life in people with chronic inflammatory skin diseases: Systematic reviews of clinical effectiveness and cost-effectiveness. Health Technol Assess 19: 1-176, 2015.

3. Lapidus CS and Kerr PE: Social impact of atopic dermatitis. Med Health R I 84: 294-295, 2001.

4. Holm JG, Agner T, Clausen ML and Thomsen SF: Quality of life and disease severity in patients with atopic dermatitis. J Eur Acad Dermatol Venereol 30: 1760-1767, 2016.
5. Apfelbacher C and Heinl D: Health-related quality of life measures in atopic dermatitis: A critical appraisal. Curr Dermatol Rep 4: 155-158, 2015.

6. Constantin MM: Value and impact of patch testing in patients with allergic contact dermatitis. Rom J Lab Med 20: 287-292, 2012.

7. Taïeb A and Stalder JF: Atopic dermatitis: severity scoring. In: Cutaneous Biometrics. Schwindt DA and Maibach HI (eds). Kluwer Academic/Plenum Publishers, New York, NY, pp93-107, 2000.

8. Guéniche A, Hennino A, Goujon C, Dahel K, Bastien P, Martin R, Jourdain R and Breton L: Improvement of atopic dermatitis skin symptoms by Vitreoscilla filiformis bacterial extract. Eur J Dermatol 16: 380-384, 2006.

9. Addor FA and Aoki V: Skin barrier in atopic dermatitis. An Bras Dermatol 85: 184-194, 2010.

10. Schlievert PM, Strandberg KL, Lin YC, Peterson ML and Leung DY: Secreted virulence factor comparison between methicillin-resistant and methicillin-sensitive Staphylococcus aureus, and its relevance to atopic dermatitis. J Allergy Clin Immunol 125: 39-49, 2010.

11. Leung DY, Harbeck R, Bina P, Reiser RF, Yang E, Norris DA, Hanifin JM and Sampson HA: Presence of IgE antibodies to staphylococcal exotoxins on the skin of patients with atopic dermatitis. Evidence for a new group of allergens. J Clin Invest 92: 1374-1380, 1993.

12. Bunikowski R, Mielke MEA, Skarabis H, Worm M, Anagnostopoulos I, Kolde G, Wahn U and Renz H: Evidence for a disease-promoting effect of Staphylococcus aureus-derived exotoxins in atopic dermatitis. J Allergy Clin Immunol 105: 814-819, 2000

13. Schmitt J, Abraham S, Trautmann F, Stephan V, Fölster-Holst R, Homey B, Bieber T, Novak N, Sticherling M, Augustin M, et al: Usage and effectiveness of systemic treatments in adults with severe atopic eczema: First results of the German Atopic Eczema Registry TREATgermany. J Dtsch Dermatol Ges 15: 49-59, 2017.

14. Hoare C, Li Wan Po A and Williams H: Systematic review of treatments for atopic eczema. Health Technol Assess 4: 1-191, 2000.

15. Darsow U, Lübbe J, Taïeb A, Seidenari S, Wollenberg A, Calza AM, Giusti F and Ring J; European Task Force on Atopic Dermatitis: Position paper on diagnosis and treatment of atopic dermatitis. J Eur Acad Dermatol Venereol 19: 286-295, 2005.

16. Schiffner R, Schiffner-Rohe J, Landthaler M and Stolz W: Treatment of atopic dermatitis and impact on quality of life: A review with emphasis on topical non-corticosteroids. Pharmacoeconomics 21: 159-179, 2003.

17. Charman CR, Morris AD and Williams HC: Topical corticosteroid phobia in patients with atopic eczema. Br J Dermatol 142: 931-936, 2000.

18. Kobayashi H, Takahashi K, Mizuno N, Kutsuna H and Ishii M: An alternative approach to atopic dermatitis: Part II-summary of cases and discussion. Evid Based Complement Alternat Med 1: $145-155,2004$

19. Ogawa M, Saiki A, Matsui Y, Tsuchimoto N, Nakakita Y, Takata Y and Nakamura T: Effects of oral intake of heat-killed Lactobacillus brevis SBC8803 (SBL88 ${ }^{\mathrm{TM}}$ ) on dry skin conditions: A randomized, double-blind, placebo-controlled study. Exp Ther Med 12: 3863-3872, 2016

20. Park MS, Song NE, Baik SH, Pae HO and Park SH: Oral administration of lactobacilli isolated from Jeotgal, a salted fermented seafood, inhibits the development of 2,4-dinitrofluorobenzene-induced atopic dermatitis in mice. Exp Ther Med 14: 635-641, 2017.

21. Lin RJ, Qiu LH, Guan RZ, Hu SJ, Liu YY and Wang GJ: Protective effect of probiotics in the treatment of infantile eczema. Exp Ther Med 9: 1593-1596, 2015.

22. Yang H, Ahn C, Choi IG, Choi WS, Park MJ, Lee SS, Choi DH and Jeung EB: Estimation of the environmental effect of natural volatile organic compounds from Chamaecyparis obtusa and their effect on atopic dermatitis-like skin lesions in mice. Mol Med Rep 12: 345-350, 2015.

23. Furue M, Furukawa F, Hide M and Takehara K: Guidelines for therapy for atopic dermatitis 2004. Jpn J Dermatol 114: 135-142, 2004.

24. Thomsen SF: Atopic dermatitis: Natural history, diagnosis, and treatment. ISRN Allergy 2014: 354250, 2014.

25. Saulite I, Roider E, Darlenksi R, Jalili A and Guenova E: Cutaneous oncology: From research to diagnosis and management. BioMed Res Int 2016: 7819428, 2016. 
26. Bridgett $\mathrm{C}$ and Norén P: Stress and atopic dermatitis. In: Stress and Skin Disorders. Springer, Cham, pp119-125, 2017.

27. Montoro J, Mullol J, Jáuregui I, Dávila I, Ferrer M, Bartra J, del Cuvillo A, Sastre J and Valero A: Stress and allergy. J Investig Allergol Clin Immunol 19: 40-47, 2009.

28. McEwen BS: Stressed or stressed out: What is the difference? J Psychiatry Neurosci 30: 315-318, 2005.

29. Montero-Marin J, Prado-Abril J, Piva Demarzo MM, Gascon S and García-Campayo J: Coping with stress and types of burnout: explanatory power of different coping strategies. PLoS One 9 e89090, 2014. doi: 10.1371/journal.pone.0089090.

30. Lander F, Friche C, Tornemand H, Andersen JH and Kirkeskov L: Can we enhance the ability to return to work among workers with stress-related disorders? BMC Public Health 9: 372, 2009.

31. Van Rhenen W, Blonk RW, van der Klink JJ, van Dijk FJ and Schaufeli WB: The effect of a cognitive and a physical stress-reducing programme on psychological complaints. Int Arch Occup Environ Health 78: 139-148, 2005.

32. Dalgard F, Kupfer J and Misery L: The Burden of Itch. In: Pruritus. Springer, Cham, pp289-294, 2016.

33. Solomon I, Voiculescu VM, Căruntu C, Lupu M, Popa A, Ilie MA, Albulescu R, Căruntu A, Tanase C, Constantin C, et al: Neuroendocrine factors and head and neck squamous cell carcinoma: An affair to remember. Dis Markers 2018: 9787831, 2018.

34. Lupu M, Căruntu A, Căruntu C, Papagheorghe LML, Ilie MA, Voiculescu V, Boda D, Constantin C, Tanase C, Sifaki M, et al: Neuroendocrine factors: The missing link in non-melanoma skin cancer (Review). Oncol Rep 38: 1327-1340, 2017

35. Căruntu C, Boda D, Constantin C, Căruntu A and Neagu M: Catecholamines increase in vitro proliferation of murine B16F10 melanoma cells. Acta Endocrinol (Bucur) 10: 545-558, 2014.

36. Căruntu C, Grigore C, Căruntu A, Diaconeasa A and Boda D: The role of stress in skin diseases. Intern Medicine-Medicina Interna 8: 73-84, 2011.

37. Căruntu C, Ghită MA, Căruntu A and Boda D: The role of stress in the multifactorial etiopathogenesis of acne. Ro Med J 58: 98-101, 2011

38. Kim SH, Hur J, Jang JY, Park HS, Hong CH, Son SJ and Chang KJ: Psychological distress in young adult males with atopic dermatitis: A cross-sectional study. Medicine (Baltimore) 94: e949, 2015.

39. Garg A, Chren MM, Sands LP, Matsui MS, Marenus KD Feingold KR and Elias PM: Psychological stress perturbs epidermal permeability barrier homeostasis: Implications for the pathogenesis of stress-associated skin disorders. Arch Dermatol 137: 53-59, 2001.

40. Arndt J, Smith N and Tausk F: Stress and atopic dermatitis. Curr Allergy Asthma Rep 8: 312-317, 2008

41. Kimata H: Enhancement of allergic skin wheal responses in patients with atopic eczema/dermatitis syndrome by playing video games or by a frequently ringing mobile phone. Eur J Clin Invest 33: 513-517, 2003.

42. Pavlovic S, Daniltchenko M, Tobin DJ, Hagen E, Hunt SP, Klapp BF, Arck PC and Peters EM: Further exploring the brain-skin connection: Stress worsens dermatitis via substance P-dependent neurogenic inflammation in mice. J Invest Dermatol 128: 434-446, 2008.

43. Moynihan JA: Mechanisms of stress-induced modulation of immunity. Brain Behav Immun 17: S11-S16, 2003.

44. Buske-Kirschbaum A, Ebrecht M, Kern S and Hellhammer DH: Endocrine stress responses in TH1-mediated chronic inflammatory skin disease (psoriasis vulgaris)-do they paralle stress-induced endocrine changes in TH2-mediated inflammatory dermatoses (atopic dermatitis)? Psychoneuroendocrinology 31 439-446, 2006

45. Ruzicka T: Atopic eczema between rationality and irrationality. Arch Dermatol 134: 1462-1469, 1998.

46. Abdulla I and Ward MR: Tako-tsubo cardiomyopathy: How stress can mimic acute coronary occlusion. Med J Aust 187: 357-360, 2007

47. García-Fernández R, García J, Concepción A, Peix A and García D: Disfunción endotelial en cardiólogos tras una guardia médica. Rev Esp Cardiol 55: 1202-1204, 2002 (In Spanish).

48. Elenkov IJ and Chrousos GP: Stress hormones, Th1/Th2 patterns, pro/antiinflammatory cytokines and susceptibility to disease. Trends Endocrinol Metab 10: 359-368, 1999.

49. DeKruyff RH, Fang Y and Umetsu DT: Corticosteroids enhance the capacity of macrophages to induce Th2 cytokine synthesis in $\mathrm{CD}^{+}$lymphocytes by inhibiting IL-12 production. $\mathrm{J}$ Immunol 160: 2231-2237, 1998.
50. Mizawa M, Yamaguchi M, Ueda C, Makino T and Shimizu T: Stress evaluation in adult patients with atopic dermatitis using salivary cortisol. BioMed Res Int 2013: 138027, 2013.

51. Filippi A, Căruntu C, Gheorghe RO, Deftu A, Amuzescu B and Ristoiu V: Catecholamines reduce transient receptor potential vanilloid type 1 desensitization in cultured dorsal root ganglia neurons. J Physiol Pharmacol 67: 843-850, 2016.

52. Căruntu C, Boda D, Musat S, Căruntu A, Poenaru E, Calenic B, Săvulescu-Fiedler I, Drăghia A, Rotaru M, Bădărău AI: Stress effects on cutaneous nociceptive nerve fibers and their neurons of origin in rats. Rom Biotechnol Lett 19: 9525-9538, 2014.

53. Urashima $R$ and Mihara $M$ : Cutaneous nerves in atopic dermatitis. A histological, immunohistochemical and electron microscopic study. Virchows Arch 432: 363-370, 1998.

54. Ostlere LS, Gordon DJ, Ayliffe MJ, Rustin MH, Pereira RS and Holden CA: Substance P binding to peripheral blood mononuclear leukocytes in atopic dermatitis. Acta Derm Venereol 77: 260-263, 1997

55. Raap U and Kapp A: Neuroimmunological findings in allergic skin diseases. Curr Opin Allergy Clin Immunol 5: 419-424, 2005.

56. Staniek V, Liebich C, Vocks E, Odia SG, Doutremepuich JD, Ring J, Claudy A, Schmitt D and Misery L: Modulation of cutaneous SP receptors in atopic dermatitis after UVA irradiation. Acta Derm Venereol 78: 92-94, 1998

57. Kang H, Byun DG and Kim JW: Effects of substance P and vasoactive intestinal peptide on interferon-gamma and interleukin-4 production in severe atopic dermatitis. Ann Allergy Asthma Immunol 85: 227-232, 2000.

58. Ding W, Stohl LL, Wagner JA and Granstein RD: Calcitonin gene-related peptide biases Langerhans cells toward Th2-type immunity. J Immunol 181: 6020-6026, 2008.

59. Elenkov IJ: Neurohormonal-cytokine interactions: Implications for inflammation, common human diseases and well-being. Neurochem Int 52: 40-51, 2008.

60. Căruntu C, Boda D, Musat S, Căruntu A and Mandache E: Stress-induced mast cell activation in glabrous and hairy skin. Mediators Inflamm 2014: 105950, 2014.

61. Järvikallio A, Harvima IT and Naukkarinen A: Mast cells, nerves and neuropeptides in atopic dermatitis and nummular eczema. Arch Dermatol Res 295: 2-7, 2003.

62. Hashimoto K, Ogawa Y, Takeshima N and Furukawa TA: Psychological and educational interventions for atopic dermatitis in adults: A systematic review and meta-analysis. Behav Change 34: 48-65, 2017

63. Gupta MA: Commentary: Psychodermatology. Clin Dermatol 31: $1-2,2013$.

64. Quaresma JAS, Sotto MN and Balato A: Inflammatory and immune-mediated cutaneous diseases. Mediators Inflamm 2017: 6793968, 2017

65. Schor J: Emotions and health: Laughter really is good medicine. Nat Med J 2: 1, 2010.

66. Thyssen JP, Hamann CR, Linneberg A, Dantoft TM, Skov L, Gislason GH, Wu JJ and Egeberg A: Atopic dermatitis is associated with anxiety, depression, and suicidal ideation, but not with psychiatric hospitalization or suicide. Allergy 73: 214-220, 2018.

67. Hayashi T, Urayama O, Kawai K, Hayashi K, Iwanaga S, Ohta M, Saito T and Murakami K: Laughter regulates gene expression in patients with type 2 diabetes. Psychother Psychosom 75: 62-65, 2006.

68. Kimata $\mathrm{H}$ : Reduction of allergen-specific IgE production by laughter. Eur J Clin Invest 34: 76-77, 2004.

69. Kimata H: Kissing reduces allergic skin wheal responses and plasma neurotrophin levels. Physiol Behav 80: 395-398, 2003

70. Kimata H: Listening to Mozart reduces allergic skin wheal responses and in vitro allergen-specific IgE production in atopic dermatitis patients with latex allergy. Behav Med 29: 15-19, 2003.

71. Kemper KJ and Danhauer SC: Music as therapy. South Med J 98: 282-288, 2005

72. Bittman BB, Berk LS, Felten DL, Westengard J, Simonton OC, Pappas J and Ninehouser M: Composite effects of group drumming music therapy on modulation of neuroendocrine-immune parameters in normal subjects. Altern Ther Health Med 7: 38-47, 2001.

73. Koyama M, Wachi M, Utsuyama M, Bittman B, Hirokawa K and Kitagawa M: Recreational music-making modulates immunological responses and mood states in older adults. J Med Dent Sci 56: 79-90, 2009

74. Bittman B, Croft DT Jr, Brinker J, van Laar R, Vernalis MN and Ellsworth DL: Recreational music-making alters gene expression pathways in patients with coronary heart disease. Med Sci Monit 19: 139-147, 2013 
75. Pauwels EK, Volterrani D, Mariani G and Kostkiewics M: Mozart, music and medicine. Med Princ Pract 23: 403-412, 2014.

76. Inui A, Asakawa A, Bowers CY, Mantovani G, Laviano A, Meguid MM and Fujimiya M: Ghrelin, appetite, and gastric motility: The emerging role of the stomach as an endocrine organ. FASEB J 18: 439-456, 2004.

77. Kimata H: Viewing humorous film improves night time wakening in children with atopic dermatitis. Indian Pediatr 44 $281-285,2007$

78. Kimata H: Increase in dermcidin-derived peptides in sweat of patients with atopic eczema caused by a humorous video. J Psychosom Res 62: 57-59, 2007.

79. Smith SD, Farrugia LL, Harris V, Lee A, Carter SR, Blaszczynski A and Fischer G: Evaluation of the influence of family and friends, and the Internet on patient perceptions of long-term topical corticosteroid use. J Dermatolog Treat 28: 642-646, 2017.

80. Shang H, Cao XL, Wan YJ, Meng J and Guo LH: IL-4 gene polymorphism may contribute to an increased risk of atopic dermatitis in children. Dis Markers 2016: 1021942, 2016.

81. Hanifin JM: Critical evaluation of food and mite allergy in the management of atopic dermatitis. J Dermatol 24: 495-503, 1997.

82. Lever R: The role of food in atopic eczema. J Am Acad Dermatol 45: S57-S60, 2001.

83. Majamaa $\mathrm{H}$ and Isolauri E: Evaluation of the gut mucosal barrier: Evidence for increased antigen transfer in children with atopic eczema. J Allergy Clin Immunol 97: 985-990, 1996.

84. Thestrup-Pedersen K and Ring J: Atopic dermatitis: Summary of the 1st Georg Rajka Symposium 1998 and a literature review. Acta Derm Venereol 79: 257-264, 1999.
85. Hammar H: Provocation with cow's milk and cereals in atopic dermatitis. Acta Derm Venereol 57: 159-163, 1977.

86. Rowlands D, Tofte SJ and Hanifin JM: Does food allergy cause atopic dermatitis? Food challenge testing to dissociate eczematous from immediate reactions. Dermatol Ther 19: 97-103, 2006.

87. Werfel T and Breuer K: Role of food allergy in atopic dermatitis. Curr Opin Allergy Clin Immunol 4: 379-385, 2004.

88. Uenishi T, Sugiura H and Uehara M: Role of foods in irregular aggravation of atopic dermatitis. J Dermatol 30: 91-97, 2003.

89. Katta R and Schlichte M: Diet and dermatitis: Food triggers. J Clin Aesthet Dermatol 7: 30-36, 3014, 2014.

90. Dhar S, Malakar R, Banerjee R, Chakraborty S, Chakraborty J and Mukherjee S: An uncontrolled open pilot study to assess the role of dietary eliminations in reducing the severity of atopic dermatitis in infants and children. Indian J Dermatol 54: 183-185, 2009.

91. Shenefelt PD: Behavioral and psychotherapeutic interventions in Dermatology. In: The Handbook of Behavioral Medicine. Mostofsky D (ed). John Wiley \& Sons, New York, NY, pp570-592, 2014.

92. Blalock JE: The immune system as the sixth sense. J Intern Med 257: 126-138, 2005.

(i)(9) This work is licensed under a Creative Common BY NO NO Attribution-NonCommercial-NoDerivatives 4.0 International (CC BY-NC-ND 4.0) License. 